\title{
Membrane perforation rate in lateral maxillary sinus floor augmentation using conventional rotating instruments and piezoelectric device-a meta-analysis
}

\author{
Corinne Jordi ${ }^{* \dagger} \mathbb{B}$, Khaled Mukaddam${ }^{\dagger}$, Jörg Thomas Lambrecht and Sebastian Kühl
}

\begin{abstract}
Objectives: Maxillary sinus augmentation (MSA) is a successful and predictable intervention with low complication rates. Perforations of the Schneiderian membrane may occur impairing the general success. The aim of this study was to compare the incidence of membrane perforations between conventional rotating instruments and piezoelectric devices in a meta-analysis.

Material and methods: An electronic research on MEDLINE and PubMed database was performed evaluating the literature from 1980 till 2016. Meta-analysis was performed with the studies matching the inclusion criteria. The incidence of perforations between conventional and piezo during the lateral maxillary sinus floor elevation was determined, and forest plots and a $t$ test for significance analysis were performed.

Results: The search provided 377 articles of which 69 could be included. Selected non-randomised and non-controlled prospective and retrospective studies were incorporated. Conventional rotary instruments were associated with a perforation rate of $24 \%$, the piezoelectric devices with $8 \%$ with statistically significant difference between both modalities $(p<0.05)$.
\end{abstract}

Conclusion: Membrane perforations in MSA may be significantly reduced applying piezoelectrical devices for MSA.

Keywords: Sinus lift, Conventional, Piezosurgery, Schneiderian membrane, Perforation, Ultrasound

\section{Review}

\section{Background}

Maxillary sinus augmentation (MSA) is a successful and predictable procedure to rehabilitate the atrophic edentulous posterior maxilla after postextractional pneumatisation of the sinus and bone loss with dental implants. Different approaches to elevate the maxillary sinus floor have been described and were originally introduced by Tatum [1,2]. The lateral approach provides drilling a window in the lateral sinus wall for access to the Schneiderian membrane. This may be performed in terms of a total osteotomy or by drilling a trap door. Then, the Schneiderian membrane is carefully separated

\footnotetext{
* Correspondence: Corinne.Gfeller@unibas.ch

${ }^{\dagger}$ Equal contributors

Department of Oral Surgery, Oral Radiology and Oral Medicine, University Center for Dental Medicine, University of Basel, Basel, Switzerland
}

and elevated from the bony sinus floor and bone or bone grafting materials are applied to fill the new space between the membrane and bony sinus floor. This approach, however, is limited by the occurrence of Schneiderian membrane perforation while drilling the bony window in the sinus wall or separating the Schneiderian membrane from the bony floor. Schneiderian membrane perforation is the most frequent complication in MSA with an incidence of 7-44\% [3, 4]. Two principal different techniques acceding and elevating the Schneiderian membrane are described. The conventional approach is performed applying rotary instruments in osteotomy which represents a risk for membrane perforation $[5,6]$, followed by the manual elevation of the membrane with hand instruments (special sinus lift kits). Alternatively, piezoelectric devices as proposed by Torella [7] and Vercelotti [8] may be applied for 
osteotomy and membrane preparation. Piezoelectric devices are specially designed for osseous surgery and use low-frequency ultrasonic vibrations. The amplitude of the micro vibrations allows a precise cut of bony structures without damaging the soft tissue [9]. Piezosurgery is being increasingly used in implant surgery, and the question rises whether the incidence of membrane perforations may be reduced using piezoelectric devices for MSA. Several cases are described, and many studies report on the occurrence of membrane perforation during MSA. However, only a few meta-analysis compare the incidence of membrane perforations associated to conventional (rotational) instruments and piezoelectric devices so far. There exist two reviews with a similar objective as ours (conventional versus piezosurgery device), one review which compared conventional sinus lift with four alternative techniques including piezosurgery and at least the review of Esposito analysing the study of Rickert et al. [10].

Atieh et al. [11] examined the intra- and postoperative events associated with the use of piezoelectric devices and conventional rotary instruments for lateral MSA in a systematic review. They included four studies with 178 lateral MSA in 120 participants. The meta-analysis did not show any significant difference between the two surgical techniques. Stacchi et al. [12] analysed the occurrence of intraoperative complications during sinus floor elevation with lateral approach and their correlations with the technique adopted by surgeons. They included 21 RCTs and 11 prospective CCTs. Rotary instruments, piezoelectric osteotomes, and manual bone scrapers were used to perform the lateral antrostomy. They found that ultrasonic devices and bone scrapers had a lower incidence (10.9 and 6.0\%) of membrane perforation compared with that of rotating instruments $(20.1 \%)$. They concluded that the thinning of the lateral wall of the sinus by using ultrasonic instruments or bone scrapers seemed to reduce the incidence of accidental sinus membrane perforations.

Geminiani et al. [13] assessed the difference in the incidence of intraoperative and postoperative complications between the conventional and alternative surgical techniques, during sinus floor augmentation surgery. This meta-analysis included 11 articles, while all compared the incidence of complications in conventional lateral window sinus augmentation surgery versus alternative techniques (osteotome: five articles, piezosurgery: four articles, sonic surgery: one article, trephine: one article). They found no statistically significant difference and concluded that the use of alternative techniques does not significantly reduce the incidence of intraoperative perforation of sinus membrane. Esposito et al. [14] researched in their review the beneficial or harmful effects of bone augmentation compared to no augmentation when undertaking a sinus lift procedure. They referred to the trial of Rickert, who undertook the comparison of rotary instruments versus piezosurgery to open a lateral window in the maxillary sinus, and found no evidence for the superiority of piezosurgery. This manuscript is a potential update exclusively on membrane perforation rate in lateral sinus augmentation procedures using conventional rotary or piezoelectric devices.

\section{Material and methods}

The database PubMed and the US National Library of Medicine were screened from January 8, 2012, to January 6, 2016, for potential studies reporting on membrane perforations during MSA from 1980 till 2015. The search was conducted independently and in duplicate by two authors (MK and JC). The following search terms were used:

MeSH Terms:

1. Piezo-surgery

2. Ultrasound

3. Ultrasonic Osteotomy

4. Maxillary Schneiderian Membrane Perforation

5. Sinus Perforation

6. Maxillary Sinus Augmentation Complications

7. Lateral Sinus Osteotomy Cross-references:

1. Piezo-surgery AND Sinus Floor Elevation

2. Piezo-surgery AND Sinus Lift

3. Piezo-surgery AND Maxillary Sinus Grafting

4. Piezo AND Maxillary Sinus Lift

5. Piezoelectric Bone Surgery AND Sinus

6. Piezo-surgery AND Maxillary Sinus Augmentation Complications

7. Piezo-surgery AND Schneiderian Membrane Perforation

8. Ultrasound AND Sinus Augmentation

9. Ultrasound AND Sinus Lift

10.Ultrasonic AND Sinus Lift

11.Ultrasonic Osteotomy AND Sinus

12.Ultrasonic AND Schneiderian Membrane Perforation

13.Sinus Elevation AND Conventional

Included were all studies reporting on the amount of membrane perforations during MSA by the lateral approach. Prospective and retrospective cohort studies and case series were also included. Both studies with splitmouth design and also studies without control group were also included. Excluded were studies describing any other procedure than the lateral approach for MSA, missing information on the occurrence of membrane perforation and in vitro studies. Titles and abstracts of the searches were initially screened for possible inclusion. After analysis of the abstracts, full-text evaluation 
was performed. Any disagreement was resolved by discussion between the authors (Fig. 1).

The following data were extracted:

1. Study characteristics: title, authors' name, year of publication, study design, number of sinus floor elevations (SFE)

2. Interventions: the use of piezoelectric devices or rotary instruments for SFE

3. Outcomes: number and percentage of membrane perforation

\section{Data synthesis}

For each study, the sample size was determined and the event rate (e.g. perforation or not) was noted in an Excel sheet. Then, a meta-analysis was performed using the Comprehensive Meta-Analysis (Version 3) (Biostat, Englewood, USA) applying the sample size of each study and the event rate (e.g. perforation of the membrane or not). The software calculates the suggested effect of the operation technique (piezo or conventional) on the specific event (perforation of the membrane). This way, the raw data were weighted on the sample size for significance analysis. Applying the weighted data forest plots were calculated, indicating the weight and the $95 \%$ confidence interval. Additionally, the random effect was calculated representing the average of all studies in the respective groups (piezo and conventional).

Finally, a significance analysis was performed between both groups in terms of a $t$ test. The significance level was set at $p<0.05$ (Figs. 2 and 3).

\section{Results}

\section{Description of studies}

Abstracts of 377 articles were screened. Of these, 69 studies matched the inclusion criteria and were consecutively analysed (Tables 1 and 2). Nine of these are randomised controlled, 22 retrospective and 32 prospective studies. Comparing both groups, in 46 studies, conventional instruments were used, and in 27 studies, piezoelectric devices were used to perform the MSA (Tables 1 and 2).

The forest plots generally show a higher perforation rate for conventional sinus lift when compared to piezosurgery (Tables 1 and 2, Figs. 2 and 3). It is obvious that studies with smaller sample size reveal higher $95 \%$ confidence intervals. The random effect for conventional sinus lift was 0.24 and for the piezo 0.08 . This difference between piezo and conventional sinus lift was statistically highly significant with $p<0.001$. (Figs. 2 and 3 ).

\section{Discussion}

The current data show that there is a statistically significant less occurrence of perforation of the Schneiderian membrane when piezosurgery is used compared to conventional approach. The reason for this difference may be explained by the technical skills of piezoelectrical surgery. Piezoelectric devices are able to cut highly mineralized bone due to its surgical power which is three times higher than normal ultrasound and the variable modulations of the powerful piezoelectric handpiece with its functional frequency of 25 to $29 \mathrm{kHz}$. Specifically designed osteotomy and osteoplasty inserts move with linear microvibrations (60 to $210 \mu \mathrm{m})$, which are ideal for

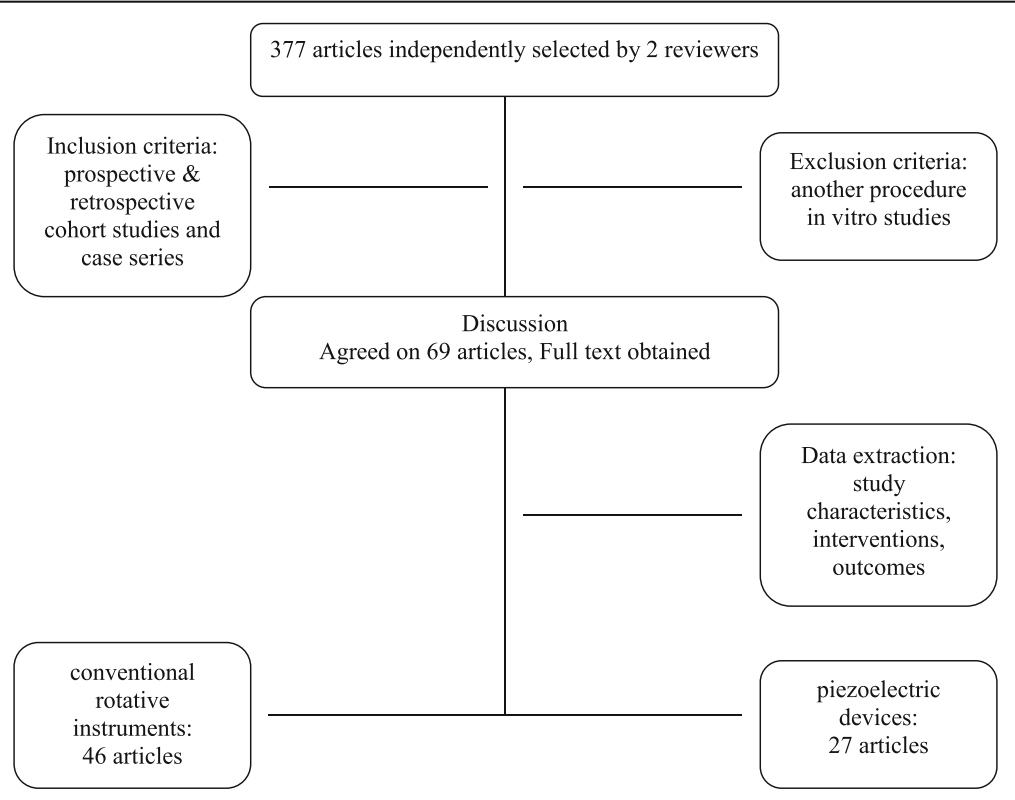

Fig. 1 Result of the search strategy and included and excluded studies 


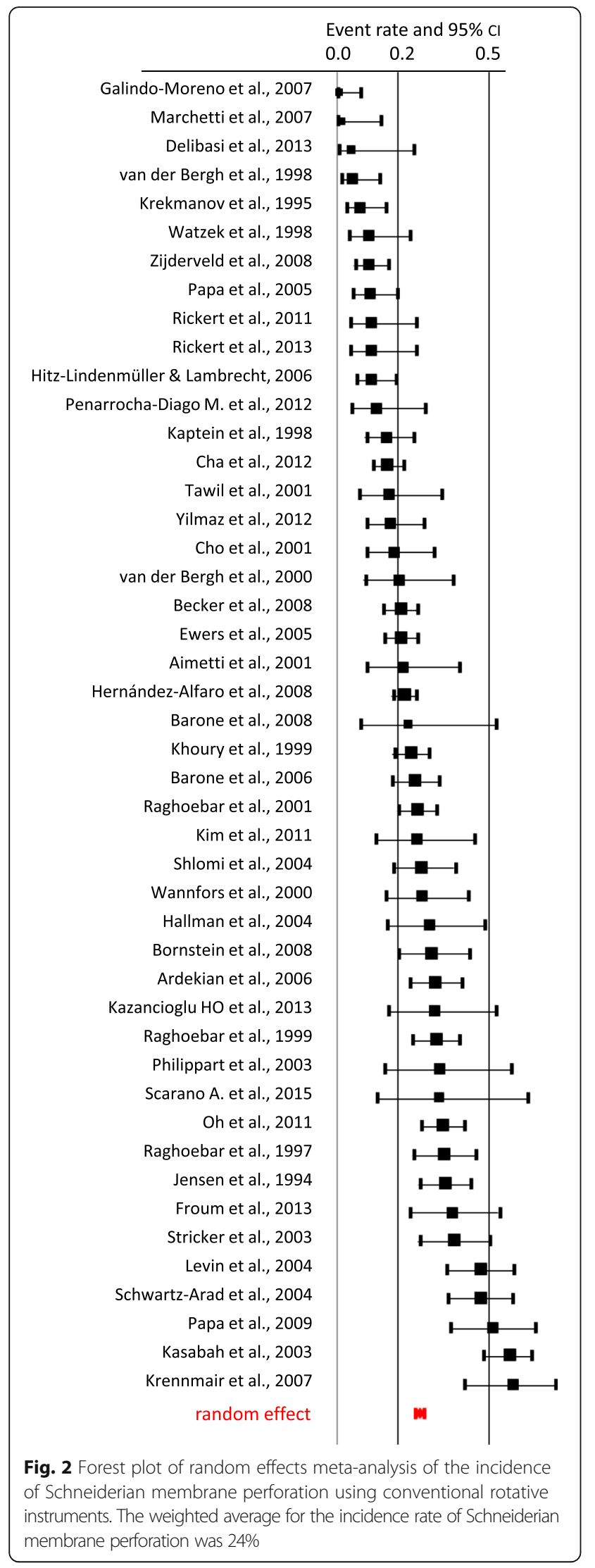

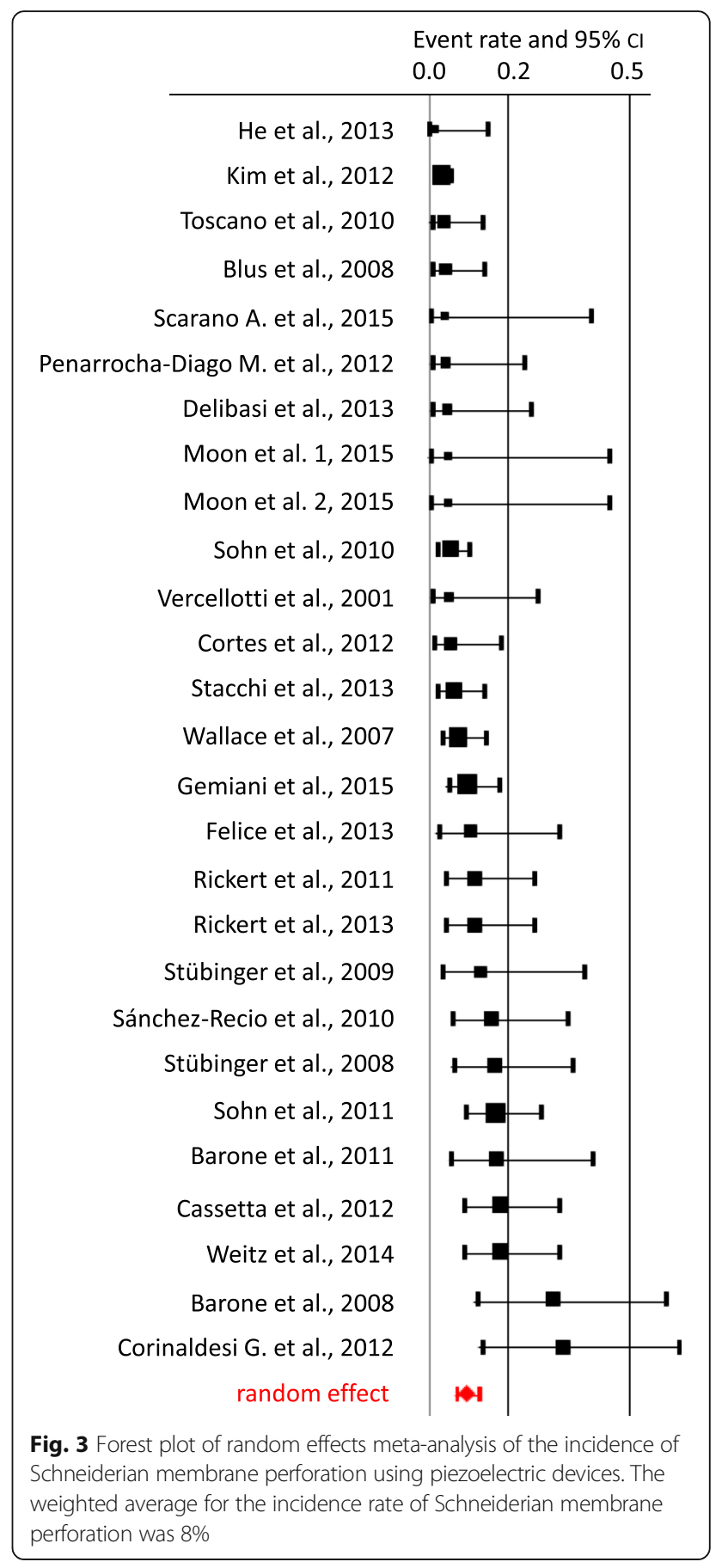

the preservation of the Schneiderian membrane. Low frequency of ultrasonics and the sharp instruments cut mineralized tissue easier than soft tissue. Furthermore, it should be noted that near soft tissue, the cutting process is safer, while not using the intrinsic cutting and using a diamond-coated instrument [8].

This aspect may be especially crucial in MSA since the facial bone is mainly compact and the Schneiderian membrane rather thin and fragile. It could be shown 
Table 1 Overview on the event rate (with lower and upper limits, z value), weight and significance ( $p$ values) for conventional approach and random effect

\begin{tabular}{|c|c|c|c|c|c|c|}
\hline Conventional & Event rate & Lower limit & Upper limit & $z$ value & $p$ value & Weight \\
\hline Galindo-Moreno et al. 2007 [15] & 0.005 & 0.000 & 0.076 & -3.726 & 0.000 & 0.445 \\
\hline Marchetti et al. 2007 [16] & 0.010 & 0.001 & 0.143 & -3.218 & 0.001 & 0.443 \\
\hline Delibasi et al. 2013 [67] & 0.043 & 0.006 & 0.252 & -3.023 & 0.003 & 0.753 \\
\hline van den Bergh et al. 1998 [5] & 0.048 & 0.016 & 0.140 & -5.033 & 0.000 & 1.507 \\
\hline Krekmanov et al. 1995 [17] & 0.071 & 0.030 & 0.160 & -5.527 & 0.000 & 1.870 \\
\hline Watzek et al. 1998 [18] & 0.100 & 0.038 & 0.238 & -4.169 & 0.000 & 1.683 \\
\hline Zijderveld et al. 2008 [19] & 0.102 & 0.059 & 0.171 & -7.153 & 0.000 & 2.394 \\
\hline Papa et al. 2005 [20] & 0.105 & 0.054 & 0.197 & -5.726 & 0.000 & 2.162 \\
\hline Rickert et al. 2011 [73] & 0.111 & 0.042 & 0.261 & -3.921 & 0.000 & 1.673 \\
\hline Rickert et al. 2013 [10] & 0.111 & 0.042 & 0.261 & -3.921 & 0.000 & 1.673 \\
\hline Lindenmüller and Lambrecht 2006 [21] & 0.112 & 0.063 & 0.191 & -6.462 & 0.000 & 2.343 \\
\hline Penarrocha-Diago et al. 2012 [22] & 0.125 & 0.048 & 0.289 & -3.640 & 0.000 & 1.661 \\
\hline Kaptein et al. 1998 [23] & 0.159 & 0.097 & 0.251 & -5.713 & 0.000 & 2.438 \\
\hline Cha et al. 2014 [24] & 0.161 & 0.118 & 0.216 & -8.932 & 0.000 & 2.765 \\
\hline Tawil et al. 2001 [25] & 0.167 & 0.071 & 0.343 & -3.285 & 0.001 & 1.791 \\
\hline Yilmaz et al. 2012 [26] & 0.172 & 0.098 & 0.284 & -4.746 & 0.000 & 2.305 \\
\hline Cho et al. 2001 [27] & 0.184 & 0.098 & 0.317 & -4.043 & 0.000 & 2.178 \\
\hline van den Bergh et al. 2000 [28] & 0.200 & 0.093 & 0.379 & -3.037 & 0.002 & 1.894 \\
\hline Becker et al. 2008 [68] & 0.204 & 0.154 & 0.265 & -7.779 & 0.000 & 2.791 \\
\hline Ewers et al. 2005 [29] & 0.206 & 0.156 & 0.266 & -7.894 & 0.000 & 2.801 \\
\hline Aimetti et al. 2001 [30] & 0.214 & 0.100 & 0.402 & -2.821 & 0.005 & 1.881 \\
\hline Hernández-Alfaro et al. 2008 [69] & 0.219 & 0.184 & 0.259 & -11.435 & 0.000 & 2.934 \\
\hline Barone et al. 2008 [31] & 0.231 & 0.076 & 0.522 & -1.829 & 0.067 & 1.346 \\
\hline Khoury et al. 1999 [3] & 0.241 & 0.188 & 0.302 & -7.217 & 0.000 & 2.831 \\
\hline Barone et al. 2006 [32] & 0.250 & 0.182 & 0.334 & -5.297 & 0.000 & 2.701 \\
\hline Raghoebar et al. 2001 [33] & 0.258 & 0.200 & 0.327 & -6.230 & 0.000 & 2.805 \\
\hline Kim et al. 2011 [34] & 0.259 & 0.129 & 0.453 & -2.391 & 0.017 & 1.948 \\
\hline Shlomi et al. 2004 [35] & 0.274 & 0.184 & 0.387 & -3.714 & 0.000 & 2.533 \\
\hline Wannfors et al. 2000 [36] & 0.275 & 0.159 & 0.432 & -2.738 & 0.006 & 2.228 \\
\hline Hallman et al. 2004 [37] & 0.300 & 0.164 & 0.483 & -2.127 & 0.033 & 2.080 \\
\hline Bornstein et al. 2008 [38] & 0.305 & 0.201 & 0.433 & -2.911 & 0.004 & 2.466 \\
\hline Ardekian et al. 2006 [39] & 0.318 & 0.238 & 0.411 & -3.723 & 0.000 & 2.709 \\
\hline Kazancioglu et al. 2013 [40] & 0.320 & 0.169 & 0.522 & -1.758 & 0.079 & 1.982 \\
\hline Raghoebar et al. 1999 [41] & 0.321 & 0.249 & 0.403 & -4.129 & 0.000 & 2.775 \\
\hline Philippart et al. 2003 [42] & 0.333 & 0.158 & 0.571 & -1.386 & 0.166 & 1.761 \\
\hline Scarano et al. 2015 [43] & 0.333 & 0.131 & 0.624 & -1.132 & 0.258 & 1.455 \\
\hline Oh et al. 2011 [44] & 0.343 & 0.276 & 0.416 & -4.085 & 0.000 & 2.830 \\
\hline Raghoebar et al. 1997 [45] & 0.346 & 0.250 & 0.455 & -2.731 & 0.006 & 2.623 \\
\hline Jensen et al. 1994 [46] & 0.352 & 0.274 & 0.438 & -3.307 & 0.001 & 2.764 \\
\hline Froum et al. 2013 [47] & 0.375 & 0.240 & 0.532 & -1.564 & 0.118 & 2.320 \\
\hline Stricker et al. 2003 [48] & 0.379 & 0.271 & 0.501 & -1.950 & 0.051 & 2.560 \\
\hline Levin et al. 2004 [49] & 0.468 & 0.362 & 0.578 & -0.562 & 0.574 & 2.648 \\
\hline
\end{tabular}


Table 1 Overview on the event rate (with lower and upper limits, z value), weight and significance ( $p$ values) for conventional approach and random effect (Continued)

\begin{tabular}{|c|c|c|c|c|c|c|}
\hline Conventional & Event rate & Lower limit & Upper limit & $z$ value & $p$ value & Weight \\
\hline Schwartz-Arad et al. 2004 [4] & 0.469 & 0.364 & 0.578 & -0.555 & 0.579 & 2.657 \\
\hline Papa et al. 2009 [50] & 0.511 & 0.371 & 0.649 & 0.146 & 0.884 & 2.437 \\
\hline Kasabah et al. 2003 [6] & 0.562 & 0.480 & 0.640 & 1.486 & 0.137 & 2.812 \\
\hline Krennmair et al. 2007 [51] & 0.575 & 0.420 & 0.717 & 0.945 & 0.345 & 2.343 \\
\hline Random & 0.240 & 0.205 & 0.278 & -11.262 & 0.000 & \\
\hline
\end{tabular}

that the mean Schneiderian membrane thickness is $1.13 \mathrm{~mm}$ [66]. Therefore, piezosurgery, with its gentle cutting process, is perfectly qualified for the maxillary sinus membrane elevation.

Though both techniques exist more than 20 years, only single studies could be found in which the incidence of membrane perforation was focused comparing both operative techniques. This was the rationale for our meta-analysis. Principally, there is a controversy in the literature concerning the use of piezosurgical devices for MSA. Torrella et al. showed a reduced risk for perforations of the sinus membrane while using ultrasound for lateral approach. They additionally mentioned the improved visibility and hygiene in the operating area and

Table 2 Overview on the event rate (with lower and upper limits, $z$ value), weight and significance ( $p$ values) for piezosurgical approach and random effect

\begin{tabular}{|c|c|c|c|c|c|c|}
\hline Piezoelectric & Event rate & Lower limit & Upper limit & $z$ value & $p$ value & Weight \\
\hline Wallace et al. 2007 [52] & 0.005 & 0.000 & 0.074 & -3.741 & 0.000 & 1.660 \\
\hline Sohn et al. 2010 [53] & 0.008 & 0.001 & 0.054 & -4.817 & 0.000 & 2.712 \\
\hline Toscano et al. 2010 [54] & 0.009 & 0.001 & 0.125 & -3.328 & 0.001 & 1.655 \\
\hline He et al. 2013 [55] & 0.010 & 0.001 & 0.143 & -3.218 & 0.001 & 1.653 \\
\hline Stübinger et al. 2008 [56] & 0.019 & 0.001 & 0.244 & -2.753 & 0.006 & 1.642 \\
\hline Kim et al. 2012 [57] & 0.028 & 0.015 & 0.052 & -11.010 & 0.000 & 6.342 \\
\hline Blus et al. 2008 [58] & 0.038 & 0.009 & 0.139 & -4.493 & 0.000 & 3.924 \\
\hline Scarano et al. 2015 [43] & 0.038 & 0.002 & 0.403 & -2.232 & 0.026 & 1.616 \\
\hline Penarrocha-Diago et al. 2012 [22] & 0.040 & 0.006 & 0.235 & -3.114 & 0.002 & 2.656 \\
\hline Delibasi et al. 2013 [67] & 0.043 & 0.006 & 0.252 & -3.023 & 0.003 & 2.649 \\
\hline Moon et al. 1 (Moon et al. 2015) [74] & 0.045 & 0.003 & 0.448 & -2.103 & 0.035 & 1.607 \\
\hline Moon et al. 2 (Moon et al. 2015) [70] & 0.045 & 0.003 & 0.448 & -2.103 & 0.035 & 1.607 \\
\hline Vercellotti et al. 2001 [8] & 0.048 & 0.007 & 0.271 & -2.924 & 0.003 & 2.642 \\
\hline Cortes et al. 2012 [59] & 0.050 & 0.013 & 0.179 & -4.059 & 0.000 & 3.900 \\
\hline Stacchi et al. 2013 [60] & 0.056 & 0.021 & 0.139 & -5.507 & 0.000 & 5.118 \\
\hline Stübinger et al. 2009 [61] & 0.063 & 0.009 & 0.335 & -2.622 & 0.009 & 2.615 \\
\hline Gemiani et al. 2015 [76] & 0.093 & 0.047 & 0.175 & -6.134 & 0.000 & 6.030 \\
\hline Felice et al. 2013 [71] & 0.100 & 0.025 & 0.324 & -2.948 & 0.003 & 3.799 \\
\hline Rickert et al. 2011 [73] & 0.111 & 0.042 & 0.261 & -3.921 & 0.000 & 5.018 \\
\hline Rickert et al. 2013 [10] & 0.111 & 0.042 & 0.261 & -3.921 & 0.000 & 5.018 \\
\hline Sánchez-Recio et al. 2010 [62] & 0.154 & 0.059 & 0.345 & -3.136 & 0.002 & 4.936 \\
\hline Sohn et al. 2011 [72] & 0.164 & 0.091 & 0.279 & -4.711 & 0.000 & 6.189 \\
\hline Barone et al. 2013 [63] & 0.167 & 0.055 & 0.409 & -2.545 & 0.011 & 4.406 \\
\hline Cassetta et al. 2012 [75] & 0.175 & 0.086 & 0.324 & -3.726 & 0.000 & 5.745 \\
\hline Weitz et al. 2014 [64] & 0.175 & 0.086 & 0.324 & -3.726 & 0.000 & 5.745 \\
\hline Barone et al. 2008 [31] & 0.308 & 0.120 & 0.591 & -1.349 & 0.177 & 4.590 \\
\hline Corinaldesi et al. 2013 [65] & 0.333 & 0.131 & 0.624 & -1.132 & 0.258 & 4.522 \\
\hline Random & 0.080 & 0.055 & 0.115 & -11.815 & 0.000 & \\
\hline
\end{tabular}


the controlled osseous incision [7]. Wallace et al. recorded a reduced membrane perforation rate, improved intraoperative visibility, reduced intraoperative bleeding and reduced surgical trauma. No perforation occurred during the antrostomy and the initial membrane elevation with piezoelectric inserts. However, using conventional hand instruments, seven membrane perforations occurred in the same study [52]. Stübinger et al. and Toscano et al. also reported on complications during the elevation with hand instruments, especially in delicate situations with underwood septa which have shown to be an additional risk for membrane perforation $[54,61]$. In contrast to these studies, Barone et al. observed four membrane perforations in the group treated with piezosurgery and only three perforations in the group treated with conventional instruments. In this randomised controlled clinical trial comparing rotary instruments with a piezoelectric device during maxillary sinus floor elevation, no significant difference was observed between the two groups. The authors concluded that the major limitation of piezosurgery was the time factor. Cutting procedures were substantially longer compared with conventional osteotomy devices [31]. Rickert et al. assessed also in a randomised controlled trial the same issue. In their study, they found no differences in the occurrence of perforations of the sinus membrane during surgery between piezo and conventional approach. They concluded that piezosurgery showed no advantages over conventional rotating instruments. Furthermore, they mentioned that the result is strongly depending on the experience of the respective surgeon with one of the respective techniques [10]. Another randomised controlled trial of Scarano et al. found a statistically significant difference between the incidences of sinus membrane perforation in the two groups. Group 1 used a round oral surgery bur, and the elevation was completed with sinus lift instruments. Group 2 using an ultrasonic surgery created a lateral bony window with nasal suction technique and elevation by using standard sinus lift instruments. Group 1 presented four perforations of the membrane, and no perforation occurred in group 2 [43].

Atieh [11] found no significant difference in perforation risk. In these studies, occurred in the two groups of the RCTs are almost identical perforations. Maybe due to the fact that they included only one RS, while our study included 22, they see no deviation.

The review of Stacchi [12] also described a lower incidence of membrane perforation during piezosurgery (10.9\%) than during conventional surgery (20.1\%). These results are comparable with ours.

Geminiani [13] found a significantly lower incidence of membrane perforations by the meta-analysis of the retrospective studies. Such a difference was not detected during meta-analysis of the data collected from the randomised clinical trials. They describe that the differences are most likely due to the inherent limitations of retrospective studies that include biases in selection of control and exposure to risk variables. They say that RCTs should be considered the main, because these trials have the preferred design for assessing differences in the outcome of a systematic review.

While incorporating selected non-randomised and non-controlled prospective and retrospective studies, our current data show that there is less perforation of the Schneiderian membrane when using piezosurgery. This might be a weakness resulting from the inclusion of the non-controlled studies.

\section{Conclusions}

The aim of the present study was to resume in a review the literature evaluating the incidence of sinus membrane perforation comparing conventional rotating instruments with piezoelectric devices. Since only scarce studies exist comparing both techniques directly, we decided to additionally include any study on MSA in which information on the applied technique, e.g. conventional or piezosurgery, was retrievable and additionally reporting on the incidence of membrane perforations. This procedure leads to heterogeneity of the collected data and accordingly included study designs. Obviously, a lot more studies with conventional approach than piezosurgery were included determining the incidence of membrane perforations. In order to reduce the resulting bias, forest plots were calculated and the weight was adjusted on the raw data, resulting in determination of the random effect. Another bias may affect the use of both conventional drilling for antrostomy and additionally piezosurgery for initial membrane elevation. The data were inconsistent in detailed information if combinations were used. Therefore, we decided to determine the piezosurgery group for both: single use for osteotomy and membrane elevation as well as for initial membrane elevation alone.

The present study may have a weakness, because membrane tear detection was not the primary focus and endpoint of many of our included studies. Many perforations might have been overlooked or not paid attention to this specific problem. The impact of different piezo tips on membrane perforation risk needs to be evaluated in further studies. With regard to our results, the present study showed that the weighted average incidence of perforation during MSA is $24 \%$ for rotating instruments and $8 \%$ for piezosurgery. These differences were statistically highly significant $(p<0.005)$. With regard to the presented results, piezosurgery can be recommended reducing the risk of membrane perforation during MSA. However, though this seems to be a 
reliable statement, it is not clear, whether combinations, e.g. osteotomy with rotating instruments and preparation of the membrane with piezosurgery, may be an alternative approach combining time efficiency with safety. The results suggest that piezosurgery was associated with a lower perforation rate. However, this statement is not reliable because of the inclusion of nonrandomised and non-controlled studies as well as retrospective data. More RCTs focusing on membrane perforation are needed for a final conclusion.

\section{Acknowledgements}

We would like to express our gratitude to Ms. Irene Mischak for the statistical support

\section{Authors' contributions}

The first two authors share the authorship. CJ and KM contributed to the data acquisition. SK, CJ and KM analysed and interpreted the data and wrote the manuscript. SK was supervising the study. JTL revised it critically and helped in finalising the manuscript and giving important intellectual content. All authors read and approved the final manuscript.

\section{Competing interests}

The authors Jordi Corinne, Mukaddam Khaled, Lambrecht Jörg Thomas and Kühl Sebastian state that they have no competing interests.

\section{Publisher's Note}

Springer Nature remains neutral with regard to jurisdictional claims in published maps and institutional affiliations.

Received: 28 September 2017 Accepted: 20 December 2017 Published online: 29 January 2018

\section{References}

1. Tatum H. Maxillary and sinus implant reconstructions. Dent Clin N Am. 1986: 30(2):207-29.

2. Boyne PJ, James RA. Grafting of the maxillary sinus floor with autogenous marrow and bone. J Oral Surg. 1980;38(8):613-6.

3. Khoury F. Augmentation of the sinus floor with mandibular bone block and simultaneous implantation: a 6-year clinical investigation. Int J Oral Maxillofac Implants. 1999;14(4):557-64.

4. Schwartz-Arad D, Herzberg R, Dolev E. The prevalence of surgical complications of the sinus graft procedure and their impact on implant survival. J Periodontol. 2004;75(4):511-6.

5. van den Bergh JP, ten Bruggenkate CM, Krekeler G, Tuinzing DB. Sinus floor elevation and grafting with autogenous iliac crest bone. Clin Oral Implants Res. 1998;9(6):429-35.

6. Kasabah S, Krug J, Simunek A, Lecaro MC. Can we predict maxillary sinus mucosa perforation? Acta Med (Hradec Kralove). 2003;46(1):19-23.

7. Torrella F, Pitarch J, Cabanes G, Anitua E. Ultrasonic ostectomy for the surgical approach of the maxillary sinus: a technical note. Int J Oral Maxillofac Implants. 1998;13(5):697-700.

8. Vercellotti T, De Paoli S, Nevins M. The piezoelectric bony window osteotomy and sinus membrane elevation: introduction of a new technique for simplification of the sinus augmentation procedure. Int J Periodontics Restorative Dent. 2001;21(6):561-7.

9. Eggers G, Klein J, Blank J, Hassfeld S. Piezosurgery: an ultrasound device for cutting bone and its use and limitations in maxillofacial surgery. Br J Oral Maxillofac Surg. 2004;42(5):451-3.

10. Rickert D, Vissink A, Slater JJ, Meijer HJ, Raghoebar GM. Comparison between conventional and piezoelectric surgical tools for maxillary sinus floor elevation. A randomized controlled clinical trial. Clin Implant Dent Relat Res. 2013;15(2):297-302.

11. Atieh MA, Alsabeeha NH, Tawse-Smith A, Faggion CM Jr, Duncan WJ. Piezoelectric surgery vs rotary instruments for lateral maxillary sinus floor elevation: a systematic review and meta-analysis of intra- and postoperative complications. Int J Oral Maxillofac Implants. 2015;30(6):1262-71.
12. Stacchi C, Andolsek F, Berton F, Perinetti G, Navarra CO, Di Lenarda R. Intraoperative complications during sinus floor elevation with lateral approach: a systematic review. Int J Oral Maxillofac Implants. 2017;32(3): e107-e18.

13. Geminiani A, Tsigarida A, Chochlidakis K, Papaspyridakos PV, Feng C, Ercoli C. A meta-analysis of complications during sinus augmentation procedure. Quintessence Int. 2017;48(3):231-40.

14. Esposito M, Felice $P$, Worthington HV. Interventions for replacing missing teeth: augmentation procedures of the maxillary sinus. Cochrane Database Syst Rev. 2014;5:CD008397.

15. Galindo-Moreno P, Avila G, Fernandez-Barbero JE, Aguilar M, SánchezFernández E, Cutando A, et al. Evaluation of sinus floor elevation using a composite bone graft mixture. Clin Oral Implants Res. 2007;18(3):376-82.

16. Marchetti C, Pieri F, Trasarti S, Corinaldesi G, Degidi M. Impact of implant surface and grafting protocol on clinical outcomes of endosseous implants. Int J Oral Maxillofac Implants. 2007;22(3):399-407.

17. Krekmanov L. A modified method of simultaneous bone grafting and placement of endosseous implants in the severely atrophic maxilla. Int J Oral Maxillofac Implants. 1995;10(6):682-8.

18. Watzek G, Weber R, Bernhart T, Ulm C, Haas R. Treatment of patients with extreme maxillary atrophy using sinus floor augmentation and implants: preliminary results. Int J Oral Maxillofac Surg. 1998;27(6):428-34.

19. Zijderveld SA, van den Bergh JP, Schulten EA, ten Bruggenkate CM. Anatomical and surgical findings and complications in 100 consecutive maxillary sinus floor elevation procedures. J Oral Maxillofac Surg. 2008; 66(7):1426-38.

20. Papa F, Cortese A, Maltarello MC, Sagliocco R, Felice P, Claudio PP. Outcome of 50 consecutive sinus lift operations. Br J Oral Maxillofac Surg. 2005;43(4):309-13.

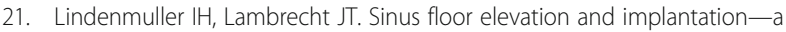
retrospective study. Schweiz Monatsschr Zahnmed. 2006;116(2):142-9.

22. Penarrocha-Diago M, Penarrocha-Diago M, Sánchez-Recio C, PenarrochaOltra D, Romero-Millan J. Osteotomy in direct sinus lift. A comparative study of the rotary technique and ultrasound. Med Oral Patol Oral Cir Bucal. 2012; 17(3):e457-61.

23. Kaptein ML, de Putter C, de Lange GL, Blijdorp PA. Survival of cylindrical implants in composite grafted maxillary sinuses. J Oral Maxillofac Surg. 1998; 56(12):1376-80. discussion 80-1

24. Cha HS, Kim A, Nowzari H, Chang HS, Ahn KM. Simultaneous sinus lift and implant installation: prospective study of consecutive two hundred seventeen sinus lift and four hundred sixty-two implants. Clin Implant Dent Relat Res. 2014;16(3):337-47.

25. Tawil G, Mawla M. Sinus floor elevation using a bovine bone mineral (BioOss) with or without the concomitant use of a bilayered collagen barrier (Bio-Gide): a clinical report of immediate and delayed implant placement. Int J Oral Maxillofac Implants. 2001;16(5):713-21.

26. Yilmaz HG, Tozum TF. Are gingival phenotype, residual ridge height, and membrane thickness critical for the perforation of maxillary sinus? J Periodontol. 2012;83(4):420-5.

27. Cho SC, Wallace SS, Froum SJ, Tarnow DP. Influence of anatomy on Schneiderian membrane perforations during sinus elevation surgery: threedimensional analysis. Pract Proced Aesthet Dent. 2001;13(2):160-3.

28. van den Bergh JP, ten Bruggenkate CM, Disch FJ, Tuinzing DB. Anatomical aspects of sinus floor elevations. Clin Oral Implants Res. 2000;11(3):256-65.

29. Ewers R. Maxilla sinus grafting with marine algae derived bone forming material: a clinical report of long-term results. J Oral Maxillofac Surg. 2005; 63(12):1712-23.

30. Aimetti M, Romagnoli R, Ricci G, Massei G. Maxillary sinus elevation: the effect of macrolacerations and microlacerations of the sinus membrane as determined by endoscopy. Int J Periodontics Restorative Dent. 2001; 21(6):581-9.

31. Barone A, Santini S, Marconcini S, Giacomelli L, Gherlone E, Covani U. Osteotomy and membrane elevation during the maxillary sinus augmentation procedure. A comparative study: piezoelectric device vs. conventional rotative instruments. Clin Oral Implants Res. 2008;19(5):511-5.

32. Barone A, Santini S, Sbordone L, Crespi R, Covani U. A clinical study of the outcomes and complications associated with maxillary sinus augmentation. Int J Oral Maxillofac Implants. 2006;21(1):81-5.

33. Raghoebar GM, Timmenga NM, Reintsema H, Stegenga B, Vissink A. Maxillary bone grafting for insertion of endosseous implants: results after 12-124 months. Clin Oral Implants Res. 2001;12(3):279-86. 
34. Kim YK, Kim SG, Park JY, Yi YJ, Bae JH. Comparison of clinical outcomes of sinus bone graft with simultaneous implant placement: 4-month and 6month final prosthetic loading. Oral Surg Oral Med Oral Pathol Oral Radiol Endod. 2011;111(2):164-9.

35. Shlomi B, Horowitz I, Kahn A, Dobriyan A, Chaushu G. The effect of sinus membrane perforation and repair with Lambone on the outcome of maxillary sinus floor augmentation: a radiographic assessment. Int J Oral Maxillofac Implants. 2004;19(4):559-62.

36. Wannfors K, Johansson B, Hallman M, Strandkvist T. A prospective randomized study of 1- and 2-stage sinus inlay bone grafts: 1-year followup. Int J Oral Maxillofac Implants. 2000;15(5):625-32.

37. Hallman M, Nordin T. Sinus floor augmentation with bovine hydroxyapatite mixed with fibrin glue and later placement of nonsubmerged implants: a retrospective study in 50 patients. Int J Oral Maxillofac Implants. 2004;19(2):222-7.

38. Bornstein MM, Chappuis V, von Arx T, Buser D. Performance of dental implants after staged sinus floor elevation procedures: 5-year results of a prospective study in partially edentulous patients. Clin Oral Implants Res. 2008;19(10):1034-43.

39. Ardekian L, Oved-Peleg E, Mactei EE, Peled M. The clinical significance of sinus membrane perforation during augmentation of the maxillary sinus. J Oral Maxillofac Surg. 2006;64(2):277-82.

40. Kazancioglu HO, Tek M, Ezirganli S, Mihmanli A. Comparison of a novel trephine drill with conventional rotary instruments for maxillary sinus floor elevation. Int J Oral Maxillofac Implants. 2013;28(5):1201-6.

41. Raghoebar GM, Batenburg RH, Timmenga NM, Vissink A, Reintsema H. Morbidity and complications of bone grafting of the floor of the maxillary sinus for the placement of endosseous implants. Mund Kiefer Gesichtschir. 1999;3(Suppl 1):S65-9.

42. Philippart P, Brasseur M, Hoyaux D, Pochet R. Human recombinant tissue factor, platelet-rich plasma, and tetracycline induce a high-quality human bone graft: a 5-year survey. Int J Oral Maxillofac Implants. 2003;18(3):411-6.

43. Scarano A, Mavriqi L, Bertelli I, Mortellaro C, Di Cerbo A. Occurrence of maxillary sinus membrane perforation following nasal suction technique and ultrasonic approach versus conventional technique with rotary instruments. J Craniofac Surg. 2015;26(3):706-8.

44. Oh E, Kraut RA. Effect of sinus membrane perforation on dental implant integration: a retrospective study on 128 patients. Implant Dent. 2011;20(1):13-9.

45. Raghoebar GM, Vissink A, Reintsema H, Batenburg RH. Bone grafting of the floor of the maxillary sinus for the placement of endosseous implants. $\mathrm{Br} \mathrm{J}$ Oral Maxillofac Surg. 1997;35(2):119-25.

46. Jensen J, Sindet-Pedersen S, Oliver AJ. Varying treatment strategies for reconstruction of maxillary atrophy with implants: results in 98 patients. J Oral Maxillofac Surg. 1994;52(3):210-6. discussion 6-8

47. Froum SJ, Khouly I, Favero G, Cho SC. Effect of maxillary sinus membrane perforation on vital bone formation and implant survival: a retrospective study. J Periodontol. 2013;84(8):1094-9.

48. Stricker A, Voss PJ, Gutwald R, Schramm A, Schmelzeisen R. Maxillary sinus floor augmentation with autogenous bone grafts to enable placement of SLA-surfaced implants: preliminary results after 15-40 months. Clin Oral Implants Res. 2003;14(2):207-12.

49. Levin L, Herzberg R, Dolev E, Schwartz-Arad D. Smoking and complications of onlay bone grafts and sinus lift operations. Int J Oral Maxillofac Implants. 2004;19(3):369-73.

50. Papa F, Cortese A, Sagliocco R, Farella M, Banzi C, Maltarello MC, et al. Outcome of 47 consecutive sinus lift operations using aragonitic calcium carbonate associated with autologous platelet-rich plasma: clinical, histologic, and histomorphometrical evaluations. J Craniofac Surg. 2009;20(6):2067-74.

51. Krennmair G, Krainhofner M, Schmid-Schwap M, Piehslinger E. Maxillary sinus lift for single implant-supported restorations: a clinical study. Int J Oral Maxillofac Implants. 2007;22(3):351-8.

52. Wallace SS, Mazor Z, Froum SJ, Cho SC, Tarnow DP. Schneiderian membrane perforation rate during sinus elevation using piezosurgery: clinical results of 100 consecutive cases. Int J Periodontics Restorative Dent. 2007;27(5):413-9.

53. Sohn DS, Moon JW, Lee HW, Choi BJ, Shin $\mathrm{H}$. Comparison of two piezoelectric cutting inserts for lateral bony window osteotomy: a retrospective study of 127 consecutive sites. Int J Oral Maxillofac Implants. 2010;25(3):571-6.

54. Toscano NJ, Holtzclaw D, Rosen PS. The effect of piezoelectric use on open sinus lift perforation: a retrospective evaluation of 56 consecutively treated cases from private practices. J Periodontol. 2010;81(1):167-71.

55. He J, Lei $Y$, Wang L. Perioperative nursing of internal sinus floor elevation surgery with piezosurgery. Hua Xi Kou Qiang Yi Xue Za Zhi. 2013;31(6):583-4.
56. Stübinger S, Landes C, Seitz O, Zeilhofer HF, Sader R. Ultrasonic bone cutting in oral surgery: a review of 60 cases. Ultraschall Med. 2008;29(1):66-71.

57. Kim JM, Sohn DS, Heo JU, Park JS, Jung HS, Moon JW, et al. Minimally invasive sinus augmentation using ultrasonic piezoelectric vibration and hydraulic pressure: a multicenter retrospective study. Implant Dent. 2012;21 (6):536-42.

58. Blus C, Szmukler-Moncler S, Salama M, Salama H, Garber D. Sinus bone grafting procedures using ultrasonic bone surgery: 5-year experience. Int J Periodontics Restorative Dent. 2008;28(3):221-9.

59. Cortes AR, Cortes DN, Arita ES. Effectiveness of piezoelectric surgery in preparing the lateral window for maxillary sinus augmentation in patients with sinus anatomical variations: a case series. Int J Oral Maxillofac Implants. 2012;27(5):1211-5.

60. Stacchi C, Vercellotti T, Toschetti A, Speroni S, Salgarello S, Di Lenarda R. Intraoperative complications during sinus floor elevation using two different ultrasonic approaches: a two-center, randomized, controlled clinical trial. Clin Implant Dent Relat Res. 2015;17(Suppl 1):e117-25.

61. Stübinger S, Saldamli B, Seitz O, Sader R, Landes CA. Palatal versus vestibular piezoelectric window osteotomy for maxillary sinus elevation: a comparative clinical study of two surgical techniques. Oral Surg Oral Med Oral Pathol Oral Radiol Endod. 2009;107(5):648-55.

62. Sánchez-Recio C, Penarrocha-Diago M, Penarrocha-Diago M, PenarrochaOltra D. Maxillary sinus lift performed using ultrasound. Evaluation of 21 patients. Med Oral Patol Oral Cir Bucal. 2010;15(2):e371-4.

63. Barone A, Ricci M, Grassi RF, Nannmark U, Quaranta A, Covani U. A 6-month histological analysis on maxillary sinus augmentation with and without use of collagen membranes over the osteotomy window: randomized clinical trial. Clin Oral Implants Res. 2013;24(1):1-6.

64. Weitz DS, Geminiani A, Papadimitriou DE, Ercoli C, Caton JG. The incidence of membrane perforation during sinus floor elevation using sonic instruments: a series of 40 cases. Int J Periodontics Restorative Dent. 2014;34(1):105-12.

65. Corinaldesi G, Piersanti L, Piattelli A, lezzi G, Pieri F, Marchetti C. Augmentation of the floor of the maxillary sinus with recombinant human bone morphogenetic protein-7: a pilot radiological and histological study in humans. Br J Oral Maxillofac Surg. 2013;51(3):247-52

66. Monje A, Diaz KT, Aranda L, Insua A, Garcia-Nogales A, Wang HL. Schneiderian membrane thickness and clinical implications for sinus augmentation: a systematic review and meta-regression analyses. J Periodontol. 2016;87(8):888-99.

67. Delilbasi C, Gurler G. Comparison of piezosurgery and conventional rotative instruments in direct sinus lifting. Implant Dent. 2013;22(6):662-5.

68. Becker ST, Terheyden H, Steinriede A, Behrens E, Springer I, Wiltfang J. Prospective observation of 41 perforations of the Schneiderian membrane during sinus floor elevation. Clin Oral Implants Res. 2008;19(12):1285-9.

69. Hernandez-Alfaro F, Torradeflot MM, Marti C. Prevalence and management of Schneiderian membrane perforations during sinus-lift procedures. Clin Oral Implants Res. 2008;19(1):91-8.

70. Moon JW, Sohn DS, Heo JU, Kim JS. Comparison of two kinds of bovine bone in maxillary sinus augmentation: a histomorphometric study. Implant Dent. 2015;24(1):19-24.

71. Felice P, Pistilli R, Piattelli M, Soardi E, Pellegrino G, Convino V, et al. 1-stage versus 2-stage lateral maxillary sinus lift procedures: 4-month post-loading results of a multicenter randomised controlled trial. Eur J Oral Implantol. 2013:6(2):153-65.

72. Sohn DS, Heo JU, Kwak DH, Kim DE, Kim JM, Moon JW, et al. Bone regeneration in the maxillary sinus using an autologous fibrin-rich block with concentrated growth factors alone. Implant Dent. 2011;20(5):389-95.

73. Rickert D, Sauerbier S, Nagursky H, Menne D, Vissink A, Raghoebar GM. Maxillary sinus floor elevation with bovine bone mineral combined with either autogenous bone or autogenous stem cells: a prospective randomized clinical trial. Clin Oral Implants Res. 2011;22(3):251-8.

74. Moon JW, Sohn DS, Heo JU. Histomorphometric analysis of maxillary sinus augmentation with calciumphosphate nanocrystal-coated xenograft. Implant Dent. 2015;24(3):333-7.

75. Cassetta M, Ricci L, lezzi G, Calasso S, Piattelli A, Perrotti V. Use of piezosurgery during maxillary sinus elevation: clinical results of 40 consecutive cases. Int J Periodontics Restorative Dent. 2012;32(6):e182-8.

76. Geminiani A, Weitz DS, Ercoli C, Feng C, Caton JG, Papadimitriou DE. A comparative study of the incidence of Schneiderian membrane perforations during maxillary sinus augmentation with a sonic oscillating handpiece versus a conventional turbine handpiece. Clin Implant Dent Relat Res. 2015; 17(2):327-34. 